\title{
The Water-Energy Nexus: Electrocoagulation and Energy Conservation
}

\author{
Avner Adin \\ Department of Soil and Water Sciences, The Hebrew University of Jerusalem, Rehovot, Israel \\ Email address: \\ avner.adin@mail.huji.ac.il \\ To cite this article: \\ Avner Adin. The Water-Energy Nexus: Electrocoagulation and Energy Conservation. Journal of Water Resources and Ocean Science. \\ Vol. 7, No. 2, 2018, pp. 15-19. doi: 10.11648/j.wros.20180702.11
}

Received: July 17, 2017; Accepted: May 15, 2018; Published: May 18, 2018

\begin{abstract}
Electrocoagulation is a multiple-purpose process re-emerging nowadays as a low-energy solution to water treatment and pollution control problems. This paper describes the development of electrocoagulation-flocculation (ECF) treatment processes of water and wastewater that could be a potential hydrogen gas source and reduce operational costs as well. ECF coupling with ultrafiltration (UF) for organics removal and flux enhancement and, with granular filtration (GF) and constructed wetland (CW) for P removal from secondary effluents are examined. Bench-scale experiments of ECF-UF and ECF-UF configurations and ECF-GF-CW pilot tests had been performed. Analysis of ECF mechanisms leads to energy conservation potential via (a) hydrogen co-generation, (b) low voltage application, (c) reduced chemicals transportation (which is also helpful in less developed cold areas where and when roads are blocked) and (d) hybridization with other low energy treatment processes such as constructed wetlands or SAT. A model developed for energy minimization is found to play a major role in process selection. It is also concluded that ECF as pretreatment for UF and MF improved filtrate quality and reduced the fouling, particularly by reducing cake influence. And, complementing $\mathrm{CW}$ treatment with a physicochemical process of ECF reduces soluble and particulate phosphate, and removes organic matter and nitrogen compounds.
\end{abstract}

Keywords: Electrocoagulation, Electroflocculation, Tertiary Treatment, Hydrogen Co-Generation, Water-Energy Nexus, Membrane Pretreatment

\section{Introduction}

Energy and water are strongly connected, particularly in cold climate regions. Water transport and treatment operations are playing a major role in that sphere. Electrochemical processes, where water and energy are so closely involved, are evolving nowadays as low-energy solutions and co-generation facilitators. Among those is electrocoagulation, which is a re-emerging multiple-purpose process involving the electrolytic addition of a coagulating metal from a sacrificial metal electrode such as aluminum or iron placed in water that hydrolyzes and coagulates colloids.

Different treatment technologies have been in practice to improve wastewater effluent quality and reclamation potentials through tertiary treatment. Coagulation is one of the key processes in this respect, which may be carried out in the conventional mode (chemical) or by electrocoagulationflocculation (ECF) process. The ECF, which is based on electrochemical method, has recently been suggested as an alternative to conventional coagulation due to its economic and environmental advantages. It has been increasingly used pretreatment of industrial wastes $[1,2]$, removal of organic $[3,4]$, inorganic pollutants $[5,6]$ and treatment of natural water [7-9]. One of the potential applications of ECF to water reuse schemes is its capability to improve performance of treatment systems via hybridization with other unit processes such as sand filtration, membrane filtration or constructed wetland $(\mathrm{CW})$.

The main objective of this study was to investigate the performance of ECF process alone or in a hybrid construction with membrane filtration and $\mathrm{CW}$ for the removal of organics (humics) and phosphorus from a wastewater secondary effluent for reuse purposes. The specific objectives included: (1) to study humics removal by hybrid ECF-Ultra filtration treatment, (2) to assess the reduction of membrane fouling potential of a hybrid ECFUF(MF) system, (3) to investigate the effectiveness of hybrid ECF-CW treatment for phosphorus removal, and (4) to point 
out the potential of hydrogen gas source for energy recovery.

This paper describes research results of electrocoagulationflocculation (ECF) treatment processes of water and wastewater that could make a potential hydrogen gas source and reduce operational costs as well.

\section{Materials and Methods}

The research consisted of the following laboratory and field (pilot) experiments of hybrid installations i) batch jar test, ii) continuous-flow, bench/semi-pilot, and iii) field, pilot plant. Wastewater samples were either synthetic solution [10] or real secondary effluent from Shafdan wastewater treatment plant (Tel Aviv Israel). ECF experiments were conducted using iron electrodes. Micro- and ultrafiltration membranes with molecular weight cut off of $4 \mathrm{kDa}$ and $150 \mathrm{kDa}$ and the $\mathrm{CW}$ were vertical flow packed with gravel beds and different plants over a three year period.

Two sets of ECF jar test experiments were carried out: the standard test and modified test (where samples were taken immediately after flocculation). The hybrid ECF-MF experiments were carried out in a stirred cell installation with varying current and contact time [11] (Figure 1). Performances were evaluated by analyses of TOC, $\mathrm{UV}_{254}$, turbidity, particle count, phosphate, aluminum and iron.

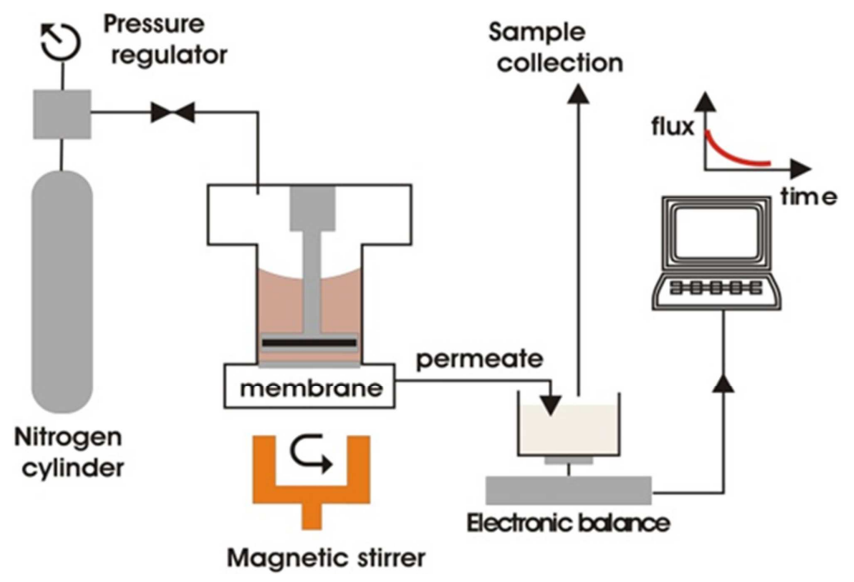

Figure 1. Stirred dead end cell for pretreatment tests [11].

\section{Results and Discussion}

\subsection{Humic Acid with ECF Treatment}

Sedimentation tests resulted in an $80-90 \% \mathrm{UV}_{254}$ removal at a low coagulant concentration and up to $80 \%$ TOC removal, although a higher coagulant concentration was required (Figures 2 and 3). At $\mathrm{pH} 7-8$ the iron is probably found as amorphous ferric oxyhydroxide or ferric hydroxide received from the oxidation of ferrous and seen by the yellow brown color in the solution. This ferric species are responsible for removing humics. The current density did not affect the overall removal indicating that the final iron concentration introduced into

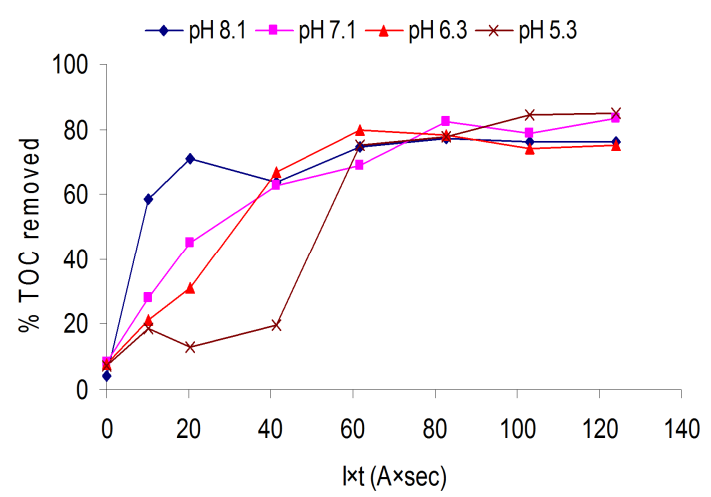

Figure 2. TOC removal with iron anode.

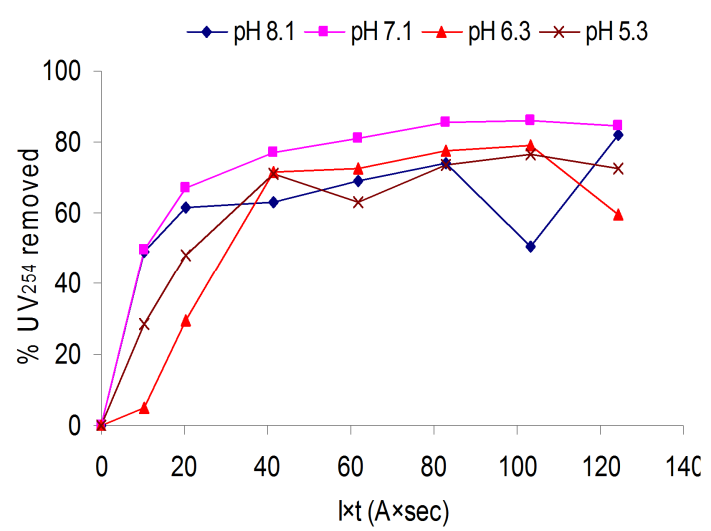

Figure 3. $U V_{254}$ removal with iron anode

The water, determines the process efficiency. This finding is in some disagreement with a recent work which indicated that ECF performance was controlled by current density, indicating that high current density and weak acidic range performs better on HA removal [12]. ECF as a pretreatment to UF membrane displayed improvement both in humic acid removal and fouling minimization. TOC and DOC removal after filtration with pretreatment was $50 \%$ higher with the two membranes tested (Table 1). The ECF reduced the fouling considerably. The initial decline in the flux curve at the beginning of the membrane filtration process, which is attributed to internal clogging mechanism, significantly improved with the pretreatment and, the flux at the end of the run was high (Figures 4 and 5).

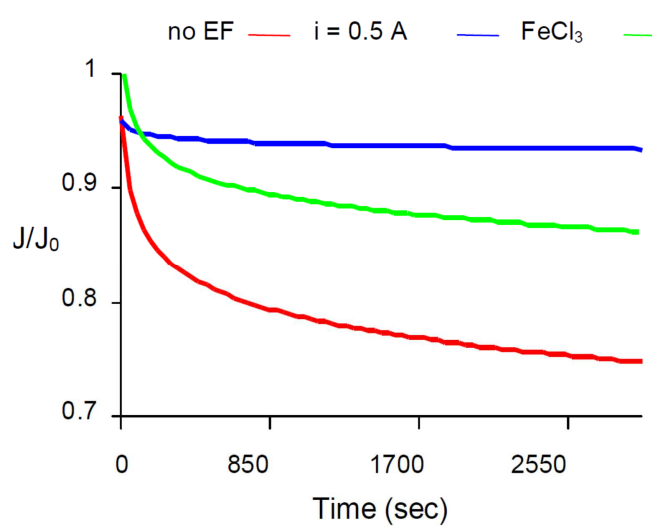

Figure 4. $4 \mathrm{KDa}$ membrane relative flux vs. time, without and with pretreatment by electrocoagulation $(I=0.5 \mathrm{~A})$ or by chemical coagulation $\left(\mathrm{FeCl}_{3}\right) \cdot \mathrm{pH} 7.1,[\mathrm{Fe}]=10 \mathrm{ppm}$. 
Table 1. TOC, DOC concentration and UV 254 absorption before and after filtration with $150 \mathrm{KDa}$ and $4 \mathrm{KDa}$ membranes with and without pretreatment.

\begin{tabular}{lllllll}
\hline & $\mathbf{T O C}_{\mathbf{i}} \mathbf{( p p m )}$ & $\mathbf{T O C}_{\mathbf{f}} \mathbf{( p p m )}$ & $\mathbf{D O C i} \mathbf{( p p m )}$ & $\mathbf{D O C}_{\mathbf{f}}(\mathbf{p p m})$ & $\mathbf{U V}_{\mathbf{2 5 4} \mathbf{i}}\left(\mathbf{c m}^{\mathbf{- 1}}\right)$ & $\mathbf{U V}_{\mathbf{2 5 4}} \mathbf{(} \mathbf{( \mathbf { c m } ^ { - 1 } )}$ \\
\hline $150 \mathrm{KDa}$ & 9.3 & 4.35 & 4.8 & 4.35 & 0.270 & 0.234 \\
$150 \mathrm{KDa}+\mathrm{ECF}$ & 9.70 & 2.30 & 3.50 & 1.80 & 0.280 & 0.080 \\
$4 \mathrm{KDa}$ & 11.30 & 3.10 & 3.05 & 2.75 & 0.200 & 0.050 \\
$4 \mathrm{KDa}+\mathrm{ECF}$ & 9.80 & 1.90 & 2.80 & 1.40 & 0.200 & 0.025 \\
\hline
\end{tabular}

$\mathrm{TOC}_{\mathrm{i}}=$ initial concentration, $\mathrm{TOC}_{\mathrm{f}}=$ concentration after filtration, $\mathrm{pH}=7.1, \mathrm{i}=0.6 \mathrm{~A}, \mathrm{~A}_{\mathrm{elec}}=9 \mathrm{~cm}^{2},[\mathrm{Fe}]=10 \mathrm{ppm}$

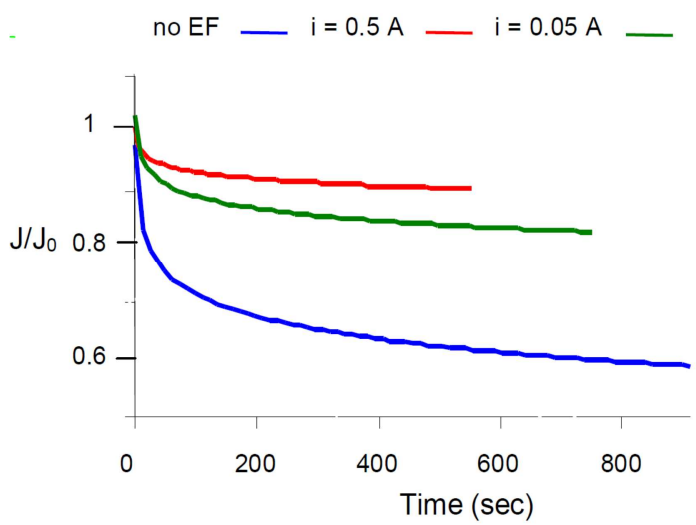

Figure 5. $150 \mathrm{KDa}$ membrane relative flux vs. time, without and with pretreatment by electrocoagulation comparing two current densities ( $I=0.5$ A, $0.05 \mathrm{~A}$ ). $\mathrm{pH} 7.1,[\mathrm{Fe}]=10 \mathrm{ppm}$.

Pretreatment with chemical coagulation gave similar results in humic acid removal, but was not as good in the cake fouling reduction.

\subsection{ECF-UF/MF of Effluents}

In membrane filtration of secondary effluents, without ECF pretreatment, severe fouling was observed. The flux reduction from fouling was higher in microfiltration than ultrafiltration. This observation demonstrated the importance of the ratio between clean membrane resistance and additional fouling resistance, rather than only the latter, with regard to fouling effect on flux. ECF pretreatment significantly mitigates membrane fouling in municipal effluents [13] as well as in high-strength industrial effluents, were membrane surface modification might be necessary [14]. In this study up to 36-fold reduction in filtration time were observed for all secondary effluents examined. In general, fouling mitigation was much higher in microfiltration than in ultrafiltration, also attributed to the ratio between clean membrane resistance and the additional fouling resistance. Comparing 10KDa ultrafiltration, 100KDa ultrafiltration and $0.1-\mu \mathrm{m}$ microfiltration of $0.75 \mathrm{~L}$ of effluent without ECF pretreatment, the shortest filtration time was observed with the $100 \mathrm{KDa}$ ultrafiltration membrane. However, with the ECF pretreatment, the filtration time in microfiltration membrane was much shorter than that with the ultrafiltration membranes (Figure 6).

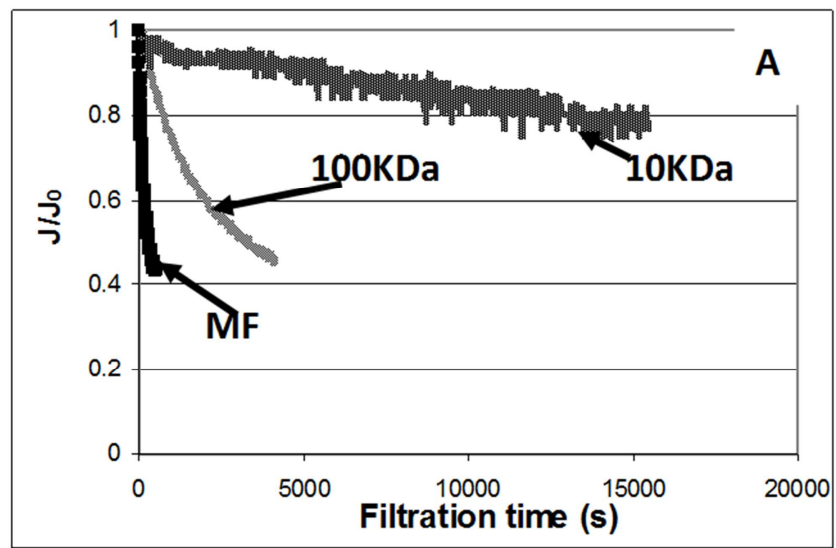

Figure 6. Normalized fluxes of EC-treated effluents for the three types of membranes.

\subsection{CW-ECF Hybridization}

CW alone removed up to $20 \%$ of TP (total P), while ECF alone removed $10-40 \%$ of TP regardless of $\mathrm{Fe}$ concentration. Filtration improved TP removal to an average of $90 \%$ when $\mathrm{Fe}$ concentration exceeds $5 \mathrm{mg} / \mathrm{l}$, with optimum $97 \%$ TP removal reaching TP concentration $<0.3 \mathrm{mg} / \mathrm{l}$. For $\mathrm{Fe}<5 \mathrm{mg} / \mathrm{l} \mathrm{TP}$ removal by $\mathrm{ECF}-\mathrm{GF}-\mathrm{CW}$ ranged between $75-89 \%$ resulting in $\mathrm{TP}$ concentration $<0.7 \mathrm{mg} / \mathrm{l}$ at all times. Earlier studies have shown similar results. When ECF-GF preceded $\mathrm{CW}$ treatment, TP removal reached a maximum of $83 \%$ for $\mathrm{Fe}>5 \mathrm{mg} / \mathrm{l}$, with $\mathrm{TP}$ concentration of $0.3-0.7 \mathrm{mg} / \mathrm{l}$. Comparing the later with the above mentioned results, $\mathrm{CW}$ consistently contributed additional phosphorous to the effluent; that could be explained by formation of a phosphorous 'reservoir' supplied by (a) Shafdan's secondary effluent between ECF treatments, and (b) plants decay, and released by water of lesser concentration. Table 2 summarizes the field pilot results of the different system configurations in this study. Extra turbidity is formed within the system by the ferrous/ferric addition. It is possible that the extra turbidity is a result of a delayed oxidation of bivalent to trivalent iron. That mechanism has to be further investigated.

Table 2. Field pilot results of different configurations.

\begin{tabular}{lllllll}
\hline & Influent & Outlet EF-GF & Outlet CW & Outlet EF-GF-CW & Outlet CW-EF-GF & No. of exp. \\
\hline TP, $\mathrm{mg} / \mathrm{l}$ & $1.40 \pm 0.54$ & $0.22 \pm 0.18$ & $1.10 \pm 0.15$ & $0.53 \pm 0.33$ & $0.17 \pm 0.04$ & 35 \\
Turbidity, NTU & $3.3 \pm 0.8$ & $3.2 \pm 1.7$ & $09 \pm 0.3$ & $2.4 \pm 0.9$ & $12 \pm 0.38$ & 30 \\
TOC, $\mathrm{mg} / \mathrm{l}$ & $12.2 \pm 2.3$ & $10.8 \pm 1.4$ & $8.0 \pm 0.8$ & $9.4 \pm 1.4$ & $6.4 \pm 0.6$ & 20 \\
TSS, $\mathrm{mg} / \mathrm{l}$ & $4.9 \pm 2.6$ & $4.8 \pm 2.1$ & $1.4 \pm 1.0$ & $2.5 \pm 1.3$ & $0.6 \pm 0.2$ & 25 \\
\hline
\end{tabular}




\subsection{Energy Conservation}

ECF may lead to energy conservation potential in one or more of several ways: (a) hydrogen co-generation, (b) low voltage application, (c) reduced chemicals transportation (which is also helpful in less developed cold areas where and when roads are blocked) (d) hybridization with other low energy treatment processes such as constructed wetlands or $\mathrm{SAT}$, and (e) reducing trans-membrane pressure by membrane fouling prevention.

During the electrochemical process the following main reactions occur near the electrodes [1]:

Near the anode:

Reaction I:

$$
M_{(s)} \rightarrow M_{(a q)}^{+n}+n e^{-}
$$

Reaction II:

$$
2 \mathrm{H}_{2} \mathrm{O} \rightarrow \mathrm{O}_{2(g)}+4 H^{+}(a q)+4 e^{-}
$$

Near the cathode

Reaction III:

$$
2 \mathrm{H}_{2} \mathrm{O}+2 e^{-} \rightarrow \mathrm{H}_{2(\mathrm{~g})}+2 \mathrm{OH}^{-}(a q)
$$

The meaning of the above reactions is that:

Of every +2 electrons - one $\mathrm{H}$ mole is formed

Of every Al mole $(+3 \mathrm{e})-1.5 \mathrm{H}$ moles are formed

Stoichiometric calculations will show that for each $9 \mathrm{~g}$ dissolution of Aluminum 1g of Hydrogen is formed.

For energy potential estimate, let's take the case of a 100 $\mathrm{m} 3 / \mathrm{h}$ ECF enhanced primary sedimentation at the wastewater treatment plant of Yavne, Israel. Iron is dosed via iron anodes at $30 \mathrm{mg} / \mathrm{L}$. Calculated Hydrogen production: $3.85 \mathrm{Kg} /$ day

Predicted gas volume, considering $25 \mathrm{~L} /$ mole: 48,000 $\mathrm{L} /$ day. Burning in air, the hydrogen $\left(\mathrm{H}_{2}\right)$ reacts with oxygen $\left(\mathrm{O}_{z}\right)$ to form water $\left(\mathrm{H}_{2} \mathrm{O}\right)$ and releases energy.

$$
2 \mathrm{H}_{2}(\mathrm{~g})+1 / 2 \mathrm{O}_{2}(\mathrm{~g}) \rightarrow 2 \mathrm{H}_{2} \mathrm{O}(\mathrm{g})
$$

Total energy released in forming $\mathrm{H}_{2} \mathrm{O}(2 \mathrm{xO}-\mathrm{H})=2 \times 462.8$ $=925.6 \mathrm{kj} / \mathrm{mole}$

If one works in a potential range below the decomposition potential of water $(1.6-1.8 \mathrm{~V})$ gas formation does not occur. If the gas formation is allowed after the coagulationflocculation phase, the separation process along the gravitational settling will be completed by electrofloatation. The separation of floating particles takes place with a much higher separation rate than that of settling. The process results in a very clean effluent with more than $90 \%$ turbidity and suspended solids removal [15].

\section{Conclusions}

(1) Electrocoagulation (ECF) can be effectively used in the removal of humic acid from water. ECF as pretreatment for
UF membrane filtration improved filtrate quality and reduced the fouling, particularly by lowering cake influence. The iron ions released from the electrode at $\mathrm{pH}$ 5.3-8.1 were found to be ferrous that probably oxidize to ferric.

(2) Iron-based ECF can provide a highly efficient method for fouling mitigation in both MF and UF of secondary effluents. ECF increases cake permeability and this leads to a reduction in external resistance. Further investigation should focus on understanding the effects of ECF on internal fouling during the filtration of secondary effluents.

(3) Complementing CW treatment with a physicochemical process of ECF can provide a tertiary treatment that effectively polishes secondary municipal effluent. While ECF effectively reduces phosphate in both soluble and particulate forms, CW treatment provides a transportattachment trap to turbidity that escapes the electro-physicochemical process and removes organic matter and $\mathrm{N}$ compounds.

(4) ECF may lead to energy conservation through hydrogen co-generation, low voltage application, reduced chemicals transportation, hybridization with other low energy treatment processes and by membrane fouling reduction.

\section{References}

[1] Mollah M. Y. A., Schennach R., Parga, J. R. \& Cocke, D. L. (2001). Electrocoagulation (EC) - science and applications. Journal of Hazardous Materials, B84 29-41.

[2] Mahesh S., B. Prasad, I. D. Mall and I. M. Mishra. 2006. Electrochemical degradation of pulp and paper mill wastewater. Part 1. COD and Color Removal. Industrial \& Engineering Chemistry Research 45 (8), 2830-2839.

[3] Monser L. and Adhoum N. 2004. Decolourization and removal of phenolic compounds from olive mill wastewater by electrocoagulation. Separation and Purification Technology 38 (3) 233-239.

[4] Ben-Sasson M. and Adin A. (2013). Enhanced removal of natural organic matter by hybrid process of electrocoagulation and dead-end microfiltration. Chemical Engineering Journal, $232,338-345$

[5] Meunier N., Drogui P., Montan'e C., Hausler R., Mercier G. and Blais F. G. 2006. Comparison between electrocoagulation and chemical precipitation for metals removal from acidic soil leachate. Journal of Hazardous Materials 137(1) 581-590.

[6] Gao P., Chen X., Shen F. and Chen G., 2005. Removal of chromium(VI) from wastewater by combined electrocoagulation - electroflotation without a filter. Separation and Purification Technology 43 117-123.

[7] Harif T. and Adin A. (2007). Characteristics of aggregates formed by electroflocculation of a colloidal suspension. Water Research, 41(13): 2951-2961.

[8] Harif T., Khai M. and Adin A. (2012). Electrocoagulation versus chemical coagulation: coagulation/flocculation mechanisms and resulting floc characteristics. Water Research 46(10) 3177-88. 
[9] Sun J., Hu C., Tong T., Zhao K., Qu J., Liu H. and Elimelech M. (2017) Performance and Mechanisms of Ultrafiltration Membrane Fouling Mitigation by Coupling Coagulation and Applied Electric Field in a Novel Electrocoagulation Membrane Reactor. Environmental Science and Technology $51,8544-8551$

[10] Egozy Y. (1996). Water recirculation through biological filter for coastal streams rehabilitation in Israel. MSc thesis, The Hebrew University of Israel and Tel-Aviv University (in Hebrew).

[11] Berenstein R., Chen Y. and Adin, A. (2007). Electrocoagulation of humic acid and its effect on membrane fouling reduction. IWA Particle Separation Conference, Amsterdam.

[12] Hu, C., Sun, J., Wang, S., Liu, R., Liu, H. and Qu, J. (2017).
Enhanced efficiency in HA removal by electrocoagulation through optimizing flocs properties: Role of current density and $\mathrm{pH}$. Separation and Purification Technology 175, 248-254.

[13] Ben-Sasson M. and Adin A. (2010). Fouling mitigation by iron-based electroflocculation in microfiltration: mechanisms and energy minimization, Water Research 44 3973-3981.

[14] Sanyal O., Liu Z., Yu J., Meharg B. M., Hong J. S., Liao W. and Lee I. (2016). Designing fouling-resistant clay-embedded polyelectrolyte multilayer membranes for wastewater effluent treatment. Journal of Membrane Science 512, 21-28.

[15] Adin A. and Vescan N. (2002). Electroflocculation for particle destabilization and aggregation for municipal water and wastewater treatment. Proc. American Chemical Society 42(2) $537-541$. 